\title{
Booster seats for child passengers: lessons for increasing their use
}

\author{
F P Rivara, E Bennett, B Crispin, K Kruger, B Ebel, A Sarewitz
}

\begin{abstract}
Objective-To explore parental knowledge, attitudes, beliefs, and barriers to use of booster seats in cars for 4-8 year old children.

Methods-Three focus groups conducted by a professional marketing firm.

Results-Many parents were confused about the appropriate weight and age of children who should be in booster seats; most parents incorrectly identified the age at which it was safe to use a lap-shoulder belt. Legislation was viewed as a positive factor in encouraging use. Cost of seats was frequently cited as a barrier to ownership, as were child resistance, peer pressure from older children, the need to accommodate other children in the vehicle, and the belief that a lap belt was adequate. Messages from health care providers, emergency medical services, or law enforcement personnel were believed to be most effective.

Conclusion-Campaigns to promote booster seat use should address issues of knowledge about appropriate age and size of the child, cost, inadequacy of lap belts, and resistance to use by the child.

(Injury Prevention 2001;7:210-213)
\end{abstract}

Keywords: motor vehicle; child passengers; seat belts

Harborview Injury Prevention and Research Center and Department of Pediatrics University of Washington, Seattle F P Rivara

B Ebel

Harborview Injury Prevention and Research Center, Seattle

A Sarewitz

Children's Hospital and Regional Medical Center, Seattle E Bennett B Crispin

Safety Restraint Coalition, Kirkland K Kruger

Correspondence to: Dr F P Rivara, Harborview Injury Prevention and Research Center, Box 359960, 325 Ninth Ave, Seattle WA 98104, USA fpr@u.washington.edu
Motor vehicle crashes are the leading cause of death for preschool and young school aged children in the United States. ${ }^{1}$ Of those killed as occupants in 1997, 46\% used no restraint. ${ }^{2}$ Safety seat, specifically booster seat, use by children 4-8 years of age is uncommon. One national survey found use to be only $6.1 \%$ in this age group, with $75.3 \%$ using lap belts prematurely. ${ }^{3}$ The risks of lap belts to young children are well documented and include spinal column and cord injuries, head injuries, and hollow viscus abdominal injuries. ${ }^{4-8}$

The National Highway Traffic Safety Administration has made promotion of booster seats for 4-8 year old children a national priority. Unfortunately, little is known about reasons for their lack of use or about effective means to promote use. To better design a booster seat promotional campaign, we used the common marketing tool of focus groups to direct and refine our message. This information can be used to help guide similar programs elsewhere.

\section{Methods}

A professional survey research firm conducted three focus groups with parents. This firm does not sell any safety products. The groups were conducted in three different socioeconomic areas of the Seattle metropolitan area to maximize diversity of the participants. Questions were asked about knowledge, attitudes, and barriers to booster seat use, campaign messages, and the medium for message delivery.

Focus group participants were recruited through fliers placed at local child and day care facilities located in the three respective neighborhoods. These fliers noted sponsorship of the focus groups by Children's Hospital and Regional Medical Center. Parents were eligible if they were English speaking and had at least one child weighing between 30 and 45 pounds $(13.5$ and $20.3 \mathrm{~kg}$ ). Participants were paid $\$ 30$ cash and given a $\$ 15$ gift certificate for the two hour focus group sessions. Discussions were audiotaped and summarized.

Herein, "child safety seats" refer to infant and toddler child restraining devices with five point restraints, whereas "booster seats" are belt positioning devices designed for children weighing 40 pounds $(18.0 \mathrm{~kg})$ or more to allow the child to be properly restrained using lap-shoulder belts. Examples of safety seats and booster seats were available to aid discussion.

The results of the focus groups were examined using the PRECEDE-PROCEED model of Green and Kreuter. ${ }^{9}$ This model has proven to be a useful tool for planning and evaluating health education and child safety campaigns, ${ }^{9}{ }^{10}$ and considers behavior change to be influenced by three categories of factors, each of which can be affected by education and policy:

- Predisposing factors include knowledge, attitudes, beliefs, values, readiness to change, and perceptions of the parent and child.

- Enabling factors include availability of resources to accomplish the behavior change, rules or laws, skills, and engineering changes.

- Reinforcing factors include rewards or incentives, social support, and the attitudes and reassurance of health care providers and peers.

\section{Results}

There were 30 participants, of whom all but three were women, and all with one or more children under the age of 10 living at home. Of the 21 children weighing 40 pounds or more, 10 were reported to use a booster seat at least some of the time. 
PREDISPOSING FACTORS

Parents believed that child safety seats for younger children were safer than either lap belts or booster seats for older children. The larger size of child safety seats and use of five point restraints appeared to parents to convey greater safety than systems for older children. Parents also liked that child safety seats could not be easily unbuckled.

Perceived positive aspects of booster seats were that they were easily portable from one vehicle to another, allowed the child to see out of the window more easily, and the child could get in and out of these seats by themselves. Some parents correctly viewed booster seats as safer than lap belts, while others were concerned that their child could slip out of a booster seat too easily.

Reasons parents gave to move their child to lap belts before they weighed 80 pounds $(36.0$ $\mathrm{kg}$ ) or were 8 years of age varied, but included inaccurate understanding of weight and age guidelines for use of lap-shoulder belts, lack of room in the car, difficulty moving the seats between vehicles, and use of lap or lapshoulder belts by older siblings who were viewed as role models for younger children. Several commented that they had a "safe" car or an obedient child, and therefore the parent could let the child use a lap belt.

Parents reported that they had not received clear or consistent information about when a child should be in a booster seat. When asked what was the ideal weight or age for moving their child from a child safety seat to a booster seat, most felt it was around 40 to 45 pounds or at 4 years of age. There was much less accurate knowledge on when it was safe to move a child to a lap shoulder belt. Ages given varied from 5 to 8 years and weights varied from 40 to 80 pounds. Some parents thought placing a child in a lap-shoulder belt depended on a combination of size and child behavior. Many also believed that the lap belt was adequate to protect children under 80 pounds or 8 years.

ENABLING FACTORS

Parents identified their health care provider's office as the best source of information on booster seats. Other cited sources of information included friends, magazines, stores, or the Safety Restraint Coalition.

Cost was frequently cited as a barrier. Most parents could only find expensive, high back booster seats, selling for $\$ 80$ to $\$ 100$. Loaner programs were unavailable. Discount coupons were believed to be a better means to lower the cost barrier than rebates because of the difficulty and time delay most had experienced in the past when obtaining rebates on other products. All agreed that a discount coupon should optimally lower the price to $\$ 20$ to $\$ 25$.

Some parents had pre-1990 model cars that were not equipped with lap-shoulder belts in the rear seat and so faced a dilemma over where to place their child safely.

REINFORCING FACTORS

Potential reinforcing factors discussed by parents were children viewing booster seats as "big kid" seats in contrast to child safety seats, and peer pressure. Currently, few older siblings or friends used booster seats. Changing peer pressure to one of an expectation of booster seat use was felt to be a major influence on increasing use. Parents also expressed the need for consistency of booster seat use when their children rode with other parents.

Current state law regarding children and seat restraints affected the views of most parents. When the focus groups were held, Washington State law required children only up to age 3 to be in child specific devices, thereby implicitly implying that children 4 and older could be safely restrained with lap-shoulder belts alone. All parents agreed that the new law, which goes into affect in July 2002 requiring children up to age 6 to be in child specific devices, would reinforce use of booster seats.

\section{IDENTIFICATION OF EFFECTIVE PUBLIC HEALTH} MESSAGES

Participants were asked what would be effective messages to promote purchase and use of booster seats. Appealing messages were those that were positive, informative, specific, and understandable. Participants included clear visuals, facts supporting the need for booster seats, and age and weight recommendations as other crucial message components. Examples of messages that appeared to have the most appeal were: " 40 to 80 pounds," " 4 to 8 years", "8 [years] or 80 [pounds]", "Too big for a booster seat? Think again", and "Not big enough for lap-shoulder belts". Parents also believed that promotional messages should target children to turn them into both users of, and advocates for, booster seats.

Messages using scare tactics with a focus on the fatal injuries that might happen to children buckled only in a lap belt were controversial. Some parents thought they were compelling, while others felt they were too frightening and thus counterproductive.

Parents believed that the most credible spokespersons for delivery of these messages to other parents were physicians, police, and emergency medical service providers because their work requires them to know the issues, and they have first hand contact with crash victims. Most believed that celebrity spokespersons would not necessarily be useful because of their lack of special expertise. An unbiased sponsor, such as a children's hospital or a safety organization, was thought to lend the most credibility to a promotional campaign. Parents felt that industry sponsored public education campaigns were not as credible.

Venues recommended for delivering the message included day care centers, preschools, physician offices, health departments, news media, and web sites. Broad dissemination in multiple venues was felt to be crucial to ensure repeated exposure to the message.

\section{Discussion}

Health education alone has generally been an ineffective means of changing behavior and decreasing the rate of occurrence of injuries. ${ }^{11}$ 
"Passive" interventions with changes in products and the environment, especially interventions brought about by legislation, have been the most effective. However, some injury control programs based on heath education to change behavior have resulted in substantial changes in behavior and a reduction in the rate of injuries. ${ }^{12}$ These include programs that focus on increasing the use of a passive intervention through a comprehensive community based campaign. ${ }^{11}$ To be effective, injury prevention programs need to be specific and focused in their message, target audience, and delivery.

Focus groups are a method qualitative researchers use to generate hypotheses or to guide the development of prevention programs. ${ }^{13}{ }^{14}$ One of the greatest strengths of qualitative research is its potential to develop possible models for influencing human behavior. ${ }^{15}$ Focus groups represent an efficient way to elicit beliefs and attitudes from small groups. ${ }^{16}$ While focus groups have been used only occasionally to guide the development of injury prevention programs, ${ }^{17-22}$ they have come into widespread use in other areas of health education and community intervention. As one recent article stated, “. . . the candor and peer interaction from focus group interviews .... is essential to developing credible and emotionally compelling interventions". ${ }^{23}$ There are over 2200 references in Medline on use of focus groups in health care. While some of the key findings from focus groups can be hypothesized by experts in the field, use of these groups provides external validation as well as new information not previously considered. The degree that parents had inaccurate knowledge about the size and age indications for booster seat use, and their desire for clear messages have had important influences on the development of our campaign.

We specifically used a professional survey research firm to conduct the focus groups so that standard procedures would be followed and for the data from the group sessions to be as valid as possible. The sessions were audiotaped and transcribed as has been recommended to increase validity of the information..$^{23}$ At least two members of the research team observed each group behind a one way mirror, aiding in the interpretation of the transcribed information. Three separate sessions in three different parts of the city were held to increase validity of the information.

There are serious limitations to focus groups, however. The sample is small and inherently non-representative; it is therefore generally inappropriate to apply statistical tests to data generated by focus groups. ${ }^{16}$ Because the sample includes volunteers recruited from day care centers used by parents of children in the target age group, it is not representative. The results from any one focus group may not be generalizable and must be weighed against other data and the experience of the investigators. In this case, information from the respondents could not be linked to socioeconomic or other characteristics of the parents.

The focus groups described in this report were useful in guiding the development of a

\section{Key points}

- Many parents have an inaccurate understanding of the weight and age guidelines for use of booster seats and use of lap-shoulder belts.

- Most parents felt they had not received clear and consistent messages about when a child should be in a booster seat.

- Parents identified their health care provider's office as the best source of information on booster seats.

- Cost of booster seats may be a barrier to sue for some families.

- Changing peer pressure would have a substantial influence on booster seat use.

- Laws on child restraints in motor vehicles affect how parents perceive the adequacy of different restraint methods.

- Parents felt the most effective educational messages would be those that are positive, informative, and specific.

booster seat promotional campaign. Put into the context of the PRECEDE-PROCEED model, ${ }^{9} 10$ they identified important knowledge and attitudinal barriers to use of booster seats. Most parents were confused about the age and size of children who should use booster seats, and the plethora of information about child occupant safety added to the confusion because the messages were often thought to be conflicting.

Cost barriers were identified in prior injury prevention campaigns and overcome with discount coupons. ${ }^{12} 24$ Combined with increased availability of the safety devices in stores, such discounts can be powerful enabling factors.

One of the most effective enabling factors for injury control is legislation. All 50 states currently have laws requiring infants and young children to be restrained in approved restraint devices. Unfortunately, the age coverage for these laws varies widely. Washington State recently became the first state in the United States to require that children 4 years and 40 pounds to 6 years or 60 pounds $(27.0$ $\mathrm{kg}$ ) be restrained in booster seats.

Finally, parents view health care providers as credible spokespersons to reinforce messages about booster seat use. Health care providers should recommend that children be in booster seats until they reach 8 years or 80 pounds. Resources for counseling families include the American Academy of Pediatrics' (AAP) family shopping guide to child safety seats (available at www.aap.org/family/famsjop.htm), the AAP one minute child safety seat checkup (available at www.aap.org/family/carseat3.htm), the National Highway Traffic Safety Administration (www.nhtsa.dot.gov), and the Washington State Booster Seat Coalition (www.boosterseat.org).

1 Centers for Disease Control and Prevention, National Center for Injury Prevention and Control. US Injury Mortality Statistics. Available on line at www.cdc.gov/ncipc/osp/ usmort.htm. 
2 National Highway Traffic Safety Administration. Children: traffic safety facts, 1997. Washington, DC: US Department traffic safety facts, 1997. Washington, DC:
of Transportation (HS 808 765), 1998 .

3 National SafeKids. Child passengers at risk in America, 1999. Washington, DC: National SafeKids Program, 1999.

4 International Road Traffic and Accident Database (OCED), May 2000. Available on line at www.bast.de irtad/english/we34.

5 Anderson PA, Rivara FP, Maier RV, et al. The epidemiology of seatbelt-associated injuries. F Trauma 1991;31:60-7.

6 Givens TG, Polley KA, Smith GF, et al. Pediatric cervical spine injury: a three-year experience. $\mathcal{F}$ Trauma 1996;41: 310-14.

7 Sturm PF, Glass RB, Sivit CJ, et al. Lumbar compression fractures secondary to lap-belt use in children. $\mathcal{F}$ Pediatr Orthop 1995;15:521-3.

8 Winston FK, Durbin DR, Kallan MJ, et al. The danger of premature graduation to seat belts for young children. Pedipremature graduation to seat

9 Green LW, Kreuter MW. Health promotion planning. An educational and ecological approach. 3rd Ed. Mountain View, cational and ecological approach.

10 Eriksen MP, Gielen AC. The application of health education principles to automobile child restraint programs. Health Educ Q 1983;10:30-55.

11 Klassen TP, MacKay JM, Moher D, et al. Communitybased injury prevention interventions. In: Behrman RE, ed. The future of children. Unintentional injuries in childhood. Los Altos: Packard Foundation, 2000: 83-110.

12 Rivara FP, Thompson DC, Thompson RS, et al. The Seattle children's bicycle helmet campaign: changes in helmet use and head injury admissions. Pediatrics 1994;93:567-9.

13 Basch CE. Focus group interview: an underutilized research technique for improving theory and practice in health education. Health Educ Q 1987;14:411-48.
14 Fontana A, Frey JH. Interviewing: the art of science. In: Denzin NK, Lincoln YS, eds. Handbook of qualitative research. Thousand Oaks, CA: Sage, 1994: 364-376.

15 Roberts H. Qualitative research methods in interventions in injury. Arch Dis Child 1997;76:487-9.

16 Grossman DC, Rhodes L. Qualitative methods in injury research. In: Rivara FP, Cummings P, Koepsell TD, et al, eds. Injury control: research methods and program evaluation. New York: Cambridge University Press, 2001.

17 Trettin L, Musham C. Using focus groups to design a community health program: what roles should volunteers play? 7 Health Care Poor Underserved 2000;11:444-55.

18 Cameron ID, Quine S. External hip protectors: likely non-compliance among high risk elderly people living in the community. Arch Gerontol Geriatr 1994;19:273-81.

19 Haught K, Grossman DC, Connell F. Parents' attitudes firearm injury prevention counseling in urban pediatric clinics. Pediatrics 1995;96:649-53.

20 Butler M, Coggan C, Norton R. A qualitative investigation into the receptivity to hip protective underwear among staff into the receptivity to hip protective underwear among staff 1998;111:383-5.

21 Howland J, Sargent J, Weitzman M, et al. Barriers to bicycle helmet use among children. Results of focus groups with fourth, fifth, and sixth graders. Am $\mathcal{F}$ Dis Child 1989;143: $741-4$.

22 Webster DW, Wilson ME, Duggan AK. Pakula parents' beliefs about preventing gun injuries to children. Pediatrics 1992;89(5 pt 1):908-14.

23 Kidd PS, Parshall MB. Getting the focus and the group: enhancing analytical rigor in focus group research. Qual Health Res 2000;10:293-308.

24 DiGuiseppi CG, Rivara FP, Koepsell TD, et al. Bicycle helmet use by children. Evaluation of a community-wide helmet campaign. $\mathcal{F A M A}$ 1989;262:2256-61.

\section{Mobile phones and motor vehicle injury}

International model Niki Taylor is the latest person whose injury can be attributed to driver distraction associated with mobile phones. Reuters reports that a car in which she was a passenger crashed into a utility pole after the driver reached down for his mobile phone. Ms Taylor had severe internal injuries but the driver and another passenger escaped serious injury (The Australian, May 2001).

\section{Boxing argy bargy in Australia}

A 29 year old boxer died in April after four days in a coma after a professional boxing bout. He was injured during the sixth round of a fight for the Victorian bantamweight championship title. Media reports stated that he had hit his head on the canvas. The initial injury sparked renewed calls by the Australian Medical Association and the Australian Federal Health Minister for a ban on boxing. The AMA Victorian branch president said while boxing's popularity had declined, voters had to join the association's push for a ban. "The AMA has expressed its opposition and it's now up to the wider community to decide if boxing is banned", he said. "We have been working with the government on smoking in public places and now on drugs, and it is up to the wider community to decide [boxing's fate]".

Federal and state governments are squaring off against each other on the issue of boxing. The Federal Health Minister wants a ban. State and territory chief medical officers have refused to back his call. During a national phone hook-up, they all expressed concern about injuries in professional boxing. But they also heard evidence that head and spinal injuries in other sports may outnumber those from boxing (ABC Radio "PM", March 2001).

\section{Parents try to stop speeding at school}

In an effort to educate motorists about speeding near schools, Neighbourhood Watch Committees and residents groups across Queensland are using radar guns. The devices are being provided by the Department of Transport and display vehicle speed on a screen. The Minister for Transport says the program's "sole purpose is to educate drivers and remind them of the correct speed limits in school zones". In suburban Brisbane one case demonstrates the need for change. A parent measured speeds outside her 7 year old daughter's school and in the $40 \mathrm{kph}$ zone drivers were measured travelling at speeds between $45 \mathrm{kph}$ and $50 \mathrm{kph}$. "The highest we've had is $70 \mathrm{kph}$, now that's dangerous!” she said. 